\title{
Long-term food restriction prevents ageing-associated central leptin resistance in wistar rats
}

\author{
C. Fernández-Galaz ${ }^{1}$, T. Fernández-Agulló1, C. Pérez ${ }^{2}$, S. Peralta ${ }^{3}$, C. Arribas $^{3}$, A. Andrés ${ }^{4}$, J. M. Carrascosa ${ }^{2}$, \\ M. $\operatorname{Ros}^{1}$ \\ ${ }^{1}$ Faculty of Health Sciences, University Rey Juan Carlos, Alcorcón, Madrid \\ 2 Center of Molecular Biology "Severo Ochoa" UAM-CSIC, Faculty of Sciences, Autonomous University, Madrid, Spain \\ ${ }^{3}$ Faculty of Environmental Sciences, University of Castilla-La Mancha, Toledo, Spain \\ ${ }^{4}$ Biochemistry Section, Faculty of Chemistry, University of Castilla-La Mancha, Ciudad Real, Spain
}

\section{Abstract}

Aims/hypothesis. Ageing is associated with insulin and leptin resistance in mammals. These alterations might be caused by the increased adiposity associated with ageing, by ageing alone or both. We studied whether leptin resistance occurs at the central level in the Wistar rat and we aimed to discriminate between the effects of ageing from those of the increased adiposity associated with ageing.

Methods. Leptin was infused intracerebroventricularly at a constant rate in young adult, old and old Wistar rats fasted for 3 months, using osmotic pumps. The effects on body weight, daily food intake, Lee index, adiposity and serum leptin values were analysed. The effect of food restriction on the expression of the long form of leptin receptor in the hypothalamus was also studied.

Results. Leptin decreased daily food intake and body weight in young and old Wistar rats. With a dose of
$10 \mu \mathrm{g} /$ day similar responses were obtained in young and old rats but with a dose of $0.2 \mu \mathrm{g} / \mathrm{day}$, only young rats showed decreases in these parameters. Foodrestriction in old rats lowered adiposity and serum leptin to values close to those of young rats, recovered responsiveness to i.c.v. administration of leptin at the dose of $0.2 \mu \mathrm{g} /$ day and increased leptin receptor expression in the hypothalamus.

Conclusion/interpretation. Our data show that old Wistar rats have a decreased response to leptin at the central level. Food-restriction recovers leptin responsiveness and increases leptin receptor in the hypothalamus suggesting that adiposity plays a key role in the development of leptin resistance associated with ageing. [Diabetologia (2002) 45:997-1003]

Keywords Leptin, leptin-resistance, food-restriction, ageing, Wistar rat.
Leptin, the product of the $o b$ gene, is mainly expressed in adipose tissue and plays a key role in the regulation of energy balance [1]. Leptin reaches its main targets in the hypothalamus, whereby after interaction with its receptor turns on signal transduction mechanisms, leading to an increase in energy expenditure and a decrease of

Received: 22 January 2002 / Revised: 27 February 2002

Published online: 19 June 2002

(C) Springer-Verlag 2002

Corresponding author: M. Ros, PhD, Facultad de Ciencias de la Salud, Universidad Rey Juan Carlos, Avda. Atenas s/n. Alcorcón, 28922 Madrid Spain, E-mail: m.ros@cs.urjc.es

Abbreviations: CSF, Cerebrospinal fluid; i.c.v., intracerebroventricular; STAT-3, signal transducer and activator of transcription 3; Ob-Rb, long isoform of leptin receptor. food intake $[2,3,4]$. This has favoured the concept that leptin acts as a feedback signal to maintain the equilibrium of the energy balance and consequently the set point of adiposity. Although this idea triggered expectations for controlling body weight, it has become clear that most cases of obesity in rodents and humans, have increased adiposity and BMI despite high serum leptin concentrations [2]. Moreover, a direct relation between adiposity or BMI and serum leptin concentrations has been described $[2,5]$. Ageing is commonly associated with increased adiposity. Elevated adiposity and serum leptin concentrations have been reported in two rat models of ageing [6,7]. Although in these cases it seems that a lack of leptin sensitivity or leptin resistance prevails, it is not clear if leptin resistance is due to ageing itself, to ageing-associated increased adiposity or both. 
There are several possible mechanisms underlying leptin resistance. Leptin transport across the bloodbrain barrier and/or the blood-cerebrospinal fluid barrier, any of the steps of the hormonal signal transduction cascade in the hypothalamus or even steps beyond the leptin-sensitive neurons are possible targets to be altered in leptin resistance states such as obesity and ageing. Alteration of leptin transport across the blood-brain barrier has been proposed to occur in obese humans [8, 9], in New Zealand obese mice [10] and in diet-induced obese mice [11]. An impairment in the leptin signal transduction cascade has been shown in the old Fisher $344 \mathrm{XBN}$ rat $[12,13]$.

Old Wistar rats are characterized by peripheral insulin resistance without overt alterations in glucose homeostasis and a moderate increase in adiposity without a considerable increment in the obesity Lee index $[7,14,15]$. These rats also show increased serum leptin concentrations during ageing, suggesting that they are leptin resistant [7]. Central leptin resistance has been reported in diet-induced obese [16] but not in old Wistar rats. The fact that old Wistar rats show a decreased uptake of leptin in hypothalamic nuclei with a lower expression of leptin receptor [7], suggest that these rats are also candidates for central leptin resistance associated with ageing. We therefore have studied the effects of i.c.v. administration of several doses of leptin for 7 days in young adult and old rats, on both, body weight loss and daily food intake. In an attempt to distinguish the role of the ageing-associated adiposity from that of ageing itself on leptin resistance, the effects of long-term food restriction on the above mentioned parameters and leptin receptor expression in the hypothalamus were also studied.

\section{Materials and methods}

Experimental animals. Young (3 months) and old (22-24 months) Wistar albino male rats, weighing $418 \pm 9 \mathrm{~g}(n=18)$ and $795 \pm 23 \mathrm{~g}(n=17)$, respectively, were obtained from the Centre of Molecular Biology "Severo Ochoa" (Madrid, Spain). Rats were housed individually in climate controlled quarters with a 12-h light cycle and handled according to the European Union laws and the National Institutes of Health (NIH) guidelines. The rats were fed a standard laboratory chow. Special care was taken to minimize animal suffering and to reduce the number of animals used.

Food restriction. 20 to 21 month-old rats $(761 \pm 18 \mathrm{~g}, n=10)$ were placed in individual cages and were fed daily with an amount of chow equivalent to 75 to $80 \%$ of the normal food intake [7] until they reached a reduction of about $25 \%$ of their body weight at the beginning of the experiment. Usually this was achieved 1 month from the start of nutritional restriction. The rats were weighed weekly and the amount of food provided was adjusted individually to maintain their weight. The average amount of chow given for maintenance was $21 \mathrm{~g}$. The rats were used at the age of 23 to 24 months.
Leptin administration. Rats were anaesthetized by inhalation of a mixture of $\mathrm{O}_{2}, \mathrm{NO}_{2}$, and isoflurane (Pharmacia-Upjohn, Barcelona, Spain) and placed in a stereotaxic frame (David Koppf, Tujunga Calif., USA). After an incision of the scalp, an unilateral opening of the skull was made with a dental drill at $-1.6 \mathrm{~mm}$ lateral to the midline and $0.8 \mathrm{~mm}$ anterior to bregma, according to Paxinos and Watson [17]. Then a cannula (4×0.36-mm length $\mathrm{x}$ diameter) connected to a mini-osmotic pump (model 2001; Alzet, Palo Alto, Calif., USA) was implanted in the right lateral cerebral ventricle. The cannula was fixed to the skull with dental cement. Osmotic minipumps, with a releasing rate of $1 \mu \mathrm{l} / \mathrm{h}$ were filled with rat-leptin (Sigma, St.Louis, Mo., USA) diluted as prescribed by the dealer. Leptin concentrations were adjusted to $0.41 \mu \mathrm{g} / \mu \mathrm{l}$ $(10 \mu \mathrm{g} / \mathrm{day})$, and $0.0082 \mu \mathrm{g} / \mu \mathrm{l}(0.2 \mu \mathrm{g} /$ day $)$ with PBS. Control rats were implanted with a minipump containing vehicle adjusted to the same osmolarity of the leptin dilution. The rats were killed under tribromoethanol anesthesia $(250 \mathrm{mg} / 100 \mathrm{~g}$ body weight) a week after the implantation of the minipumps and visceral fat was removed and weighed to assess adiposity. During the leptin or vehicle administration, food-restricted rats were allowed free access to food.

Immunohistochemical detection of leptin receptors. Immunohistochemical detection of leptin receptor was carried out as described before [7]. Briefly, $40 \mu \mathrm{m}$ coronal sections of the hypothalamus from cardially perfused and fixed rats with $4 \%$ paraformaldehyde in phosphate buffer $\mathrm{pH} 7.4$ were treated to block endogenous peroxidase with $1 \% \mathrm{H}_{2} \mathrm{O}_{2}$ in phosphate buffer saline and incubated for $48 \mathrm{~h}$ at $4{ }^{\circ} \mathrm{C}$ with goat polyclonal antiserum against a peptide mapping at the carboxy terminus of mouse leptin receptor (M-18; dilution 6:1000; sc 1834, lot No. k159, Santa Cruz Biotechnology, Santa Cruz, Calif., USA) in PBS containing $0.02 \%$ Triton-X-100, $1 \%$ gelatin, and $5 \%$ foetal bovine serum. After three rinses in PBS, sections were processed according to the immunoperoxidase procedure (ABC kit, elite, Vector Burlingame, Calif., USA) using 3-3'diaminobenzidine as chromogen combined with nickel enhancement [19]. After several rinses in PBS, sections were mounted in slide glasses, dried, dehydrated gradually in ethanol, cleared in xylene and covered with DEPEX (Serva, Heidelberg, Germany). In control sections, omitting the primary antibody, no immunoreaction was seen.

RNA extraction and RT-PCR. Hypothalami were dissected and total RNA was isolated using an RN-easy mini kit (Qiagenref.74104). The cDNA was synthesized from $5 \mu \mathrm{g}$ of DNasetreated RNA [20] by using the reverse-transcriptase activity from Moloney murine leukaemia virus (Gibco-BRL Cergy Pantoise, France), and pd[N] $]_{6}$ (Boehringer Mannheim, Germany) as a random primer. The reactions were done in $20 \mu \mathrm{l}$, and then diluted to $100 \mu \mathrm{l}$, of which $15 \mu \mathrm{l}$ were used as a template for $\mathrm{Ob}-\mathrm{Rb}-\mathrm{PCR}$ reactions, and $5 \mu \mathrm{l}$ for actin ones. The forward primer for Ob-Rb PCR was 5'-GCATGCAGAATCACTGATATTTGG-3' and the reverse primer was 5'-TGGATAAACCCTTGCTCTTCA-3'. Both were synthesized according to the published sequence for the long form $(\mathrm{Ob}-\mathrm{Rb})$ of the rat leptin receptor [21] and flank a 318 bp fragment (nucleotides 2756-3074). The rat actin primers were 5'-GGTATGGAATCCTGTGGCATCCATGAAA-3' for the 5' end, and 5'-GTGTAAAACGCAGCTCAGTAACAGTCC-3' for the $3^{\prime}$ end. Both primers flank a 356 bp fragment [22]. The PCR reactions were done in a total volume of $50 \mu \mathrm{l}$ with 1 unit of thermostable DNA polymerase from Thermus thermophilus (Biotools). The template was denatured for $5 \mathrm{~min}$ at $94^{\circ} \mathrm{C}$, followed by 35 cycles (30 cycles for actin amplification) with the following temperatures: denaturation $1 \mathrm{~min}$ at $94^{\circ} \mathrm{C}$, annealing $2 \mathrm{~min}$ at 
$55^{\circ} \mathrm{C}$ and elongation for $1 \mathrm{~min}$ at $72^{\circ} \mathrm{C}$. Reactions were finished with a final extension of $10 \mathrm{~min}$ at $72^{\circ} \mathrm{C}$. After the reaction, the samples were electrophoresed in $2.5 \%$ agarose gels, and the amplified bands were analysed with Kodak digital science 1D program (Rochester, N.Y., USA). Relative amount of amplification was calculated in each sample and expressed as ng amplified cDNA from Ob-Rb/ng amplified cDNA from actin used as control of amplification. Control reactions with different number of cycles were done previously to select conditions of amplification in the linearity range.

Other analytical procedures. Food consumption was measured daily from the difference between the amount of food provided and the amount remaining. This parameter was followed since a week before minipump implantation until the rats were killed. Body weight was also measured daily during the same period of time. Blood samples were taken from the tail vein of rats fasted overnight. Serum leptin was measured using a radioimmunoassay kit (Linco Research, St. Charles, Mo., USA). Adiposity and Lee index were calculated as described before [6]. $\Delta$ Lee index expresses the difference between Lee index values calculated at the start and at the end of the treatment.

Statistical analysis. Statistical comparisons were done by oneway or two-way analysis of variance (ANOVA) using the Prophet software (BNN Systems and Technologies, Cambridge, Mass., USA). When significant differences were found, the Duncan post hoc test was used to analyse differences between means. A $p$ value of 0.05 or less was considered for significant differences.

\section{Results}

Chronic treatment with leptin is accompanied with a decrease in body weight in different experimental models. The decrease in body weight after 6 days of treatment with saline and different doses of leptin in young and old rats is shown (Fig. 1). A decrease in body weight was observed in rats treated with saline and was higher in the old rats. Nevertheless, after subtracting these losses from those achieved with leptin treatments (Fig. 1), a specific effect of leptin was observed in both groups of rats. With a leptin dose of $0.2 \mu \mathrm{g} /$ day, young rats had a decrease in body weight compared with the control rats treated with saline. This leptin dose seems to be saturating for young rats since a further increment in the amount of leptin infused up to $10 \mu \mathrm{g} /$ day, did not induce greater losses of weight. In old rats, infusion of $0.2 \mu \mathrm{g} /$ day of leptin did not induce a body weight decrease different from that observed in the control saline-treated rats. In contrast, the dose of $10 \mu \mathrm{g} /$ day of leptin caused a greater loss of body weight than in saline-treated rats. These data show that leptin, with the highest dose used (10 $\mu \mathrm{g} /$ day), brings about a significant and specific response (Fig. 1) in both young and old rats; although, with the lower dose $(0.2 \mu \mathrm{g} /$ day $)$, only young animals showed a specific and significant response in body weight loss.

The mean daily food intake for both young and old rats during the following 6 days after pump implantation is shown (Fig. 2). Similar decreases in this
Leptin

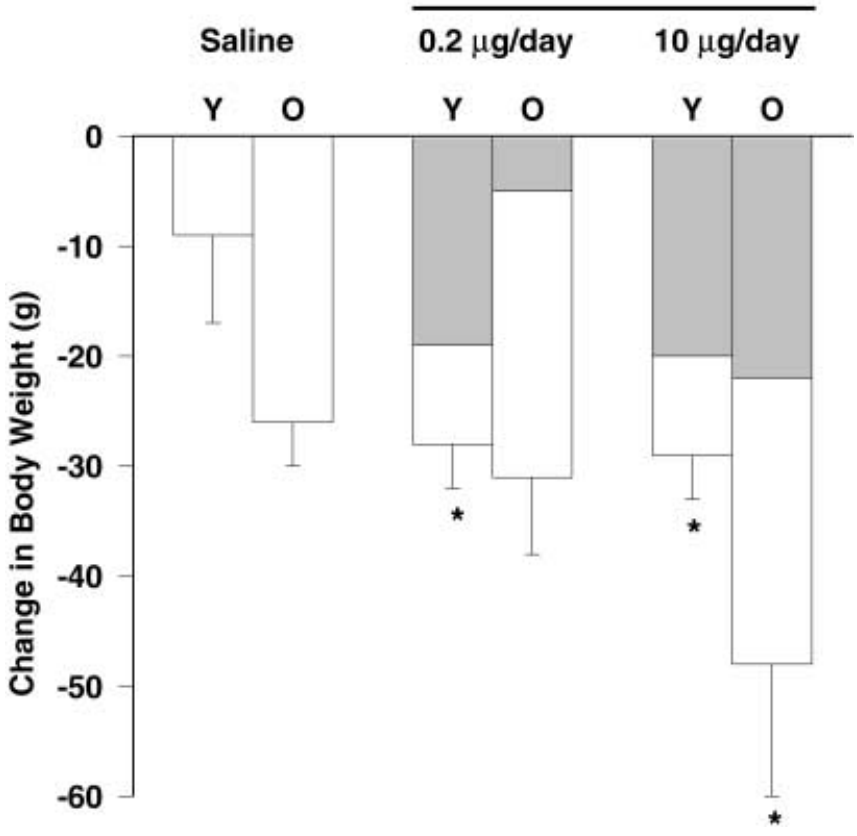

Fig. 1. Change in body weight due to leptin treatment: Change in body weight in young $(\mathrm{Y})$ and old $(\mathrm{O})$ rats after 6 days of i.c.v. administration of saline or leptin at the indicated doses as described in Methods. Grey bars represent changes in body weight specifically due to leptin treatment, after subtracting the change in body weight observed in each saline. Data are means \pm SEM of 5-6 animals per group. One-way ANOVA indicates significant effect of leptin treatment on body weight compared with values in vehicle-treated rats in young $(p<0.03)$ and old animals $(p=0.05)$. ${ }^{*} p<0.05$, different from the salinetreated rats

parameter were obtained in both groups of rats with the highest dose of leptin probed. However, when a lower dose of leptin was used $(0.2 \mu \mathrm{g} /$ day $)$, a lower response was observed in the old rats compared with young adult rats. The mean daily food intake in rats infused with saline was similar for both, young and old rats.

In an attempt to discriminate between the effects of ageing-associated adiposity from those of ageing, old rats were maintained under food restriction for 3 months, and the effect of i.c.v. administration of leptin at the dose that was effective in young but not in old rats was studied. Decreases in adiposity (from $4.9 \pm 0.3$ to $2.4 \pm 0.3 ; p<0.001$ ) and Lee index (from $319 \pm 3$ to $302 \pm 4$; $p=0.0013$ ) were found in food-restricted rats compared with the old rats fed ad libitum. The variations of these parameters and serum leptin concentrations after i.c.v. administration of leptin to young, old and food-restricted old rats is shown (Table 1). Saline infused old rats had higher serum leptin concentrations and adiposity index than saline infused young rats. According to the changes in body weight (Fig. 1), an effect of leptin on the $\Delta$ Lee index is observed in young but not in old rats. Lower adiposity was only found in young rats after treatment with the highest dose of leptin. Saline infused food-restricted old rats had a serum leptin concentration 
Table 1. Changes in serum leptin, Lee index and Adiposity index after i.c.v. leptin treatment of young, old, and food-restricted old Wistar rats

\begin{tabular}{|c|c|c|c|c|c|c|c|c|c|}
\hline \multirow{2}{*}{$\begin{array}{l}\text { Leptin } \\
{[\mu \mathrm{g} / \text { day }]}\end{array}$} & \multicolumn{3}{|c|}{ 3-month old } & \multicolumn{3}{|c|}{ 24-month old } & \multicolumn{3}{|c|}{ 24-month old food-restricted } \\
\hline & $\begin{array}{l}\Delta \text { Lee } \\
\text { Index }\end{array}$ & $\begin{array}{l}\text { Adiposity } \\
\text { Index [\%] }\end{array}$ & $\begin{array}{l}\text { Leptin } \\
{[\mathrm{ng} / \mathrm{ml}]}\end{array}$ & $\begin{array}{l}\Delta \text { Lee } \\
\text { Index }\end{array}$ & $\begin{array}{l}\text { Adiposity } \\
\text { Index [\%] }\end{array}$ & $\begin{array}{l}\text { Leptin } \\
{[\mathrm{ng} / \mathrm{ml}]}\end{array}$ & $\begin{array}{l}\Delta \text { Lee } \\
\text { Index }\end{array}$ & $\begin{array}{l}\text { Adiposity } \\
\text { Index [\%] }\end{array}$ & $\begin{array}{l}\text { Leptin } \\
{[\mathrm{ng} / \mathrm{ml}]}\end{array}$ \\
\hline 0 & $-2.1 \pm 2.0$ & $2.6 \pm 0.2$ & $1.4 \pm 0.1$ & $-4.5 \pm 1.0$ & $4.0 \pm 0.8^{b}$ & $8.8 \pm 2.7^{b}$ & $8.0 \pm 1.8^{\mathrm{c}}$ & $3.2 \pm 0.5$ & $2.7 \pm 0.4^{\mathrm{c}}$ \\
\hline 0.2 & $-6.9 \pm 1.1^{\mathrm{a}}$ & $2.1 \pm 0.5$ & $1.4 \pm 0.4$ & $-4.2 \pm 1.0$ & $4.0 \pm 0.3^{\mathrm{b}}$ & $9.0 \pm 3.2^{b}$ & $0.3 \pm 1.1^{\text {a c }}$ & $3.1 \pm 0.4$ & $1.4 \pm 0.2^{\text {a c }}$ \\
\hline
\end{tabular}

$p<0.05$ were considered for significant differences

a $p<0.05$ significantly different compared with the same group treated with saline

${ }^{\mathrm{b}} p<0.05$ significantly different compared with 3-month-old rats ${ }^{c} p<0.05$ significantly different compared with 24-month-old rats.

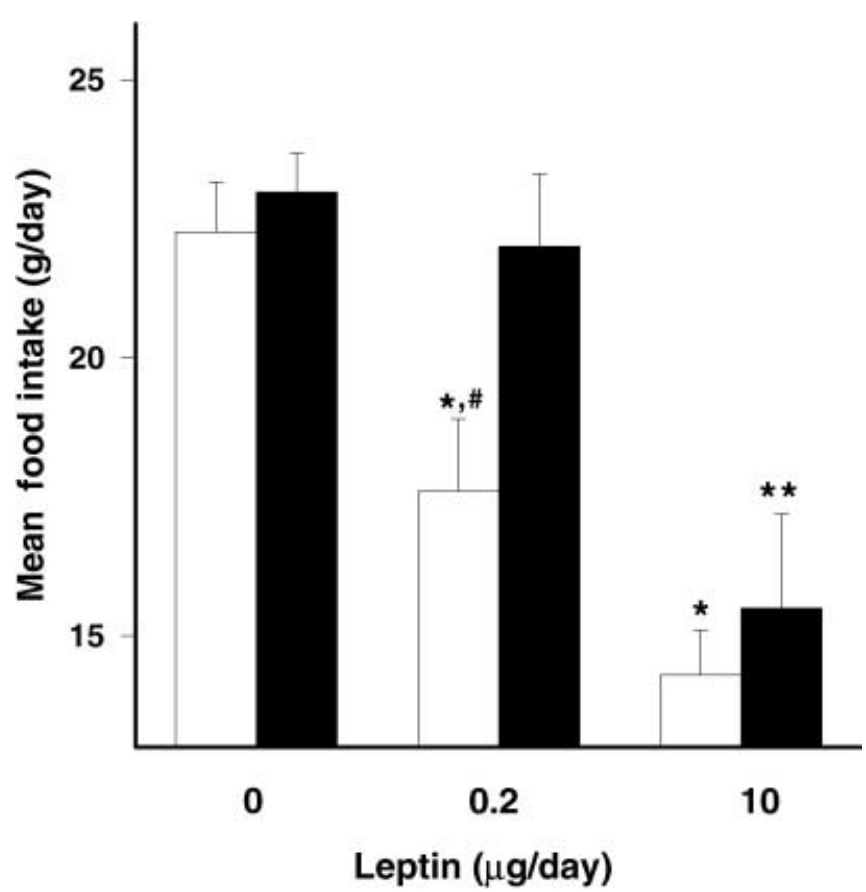

Fig. 2. Mean daily food intake during leptin treatment: Young (white bars) and old (black bars) rats were treated i.c.v. with the indicated doses of leptin by means of osmotic minipumps implanted as indicated in Methods. For each rat the mean daily food intake was calculated during treatment. Data are means \pm SEM of $5-6$ animals per group of treatment. $* p<0.05$ $* * p<0.01$; significantly different from saline-treated rats; ${ }^{\#} p<0.05$; significantly different from old rats

and adiposity index close to those of young rats. In these rats, i.c.v. administration of leptin at $0.2 \mu \mathrm{g} /$ day had an effect, preventing the increase in Lee index observed in rats infused with vehicle.

In comparisons between young and old rats, twoway ANOVA showed an effect of leptin treatment on $\Delta$ Lee Index $(p=0.006)$ and an effect of age on adiposity index $(p=0.0002)$ and serum leptin concentrations $(p=0.0029)$. In comparisons between rats fed ad libitum and food-restricted old rats, a two-way ANOVA n.d., not determined

Table shows changes in serum leptin, Lee index and adiposity index after i.c.v. administration of saline or leptin during 6 days as described in Methods. Data are expressed as means \pm SEM of 5-6 different rats in each group

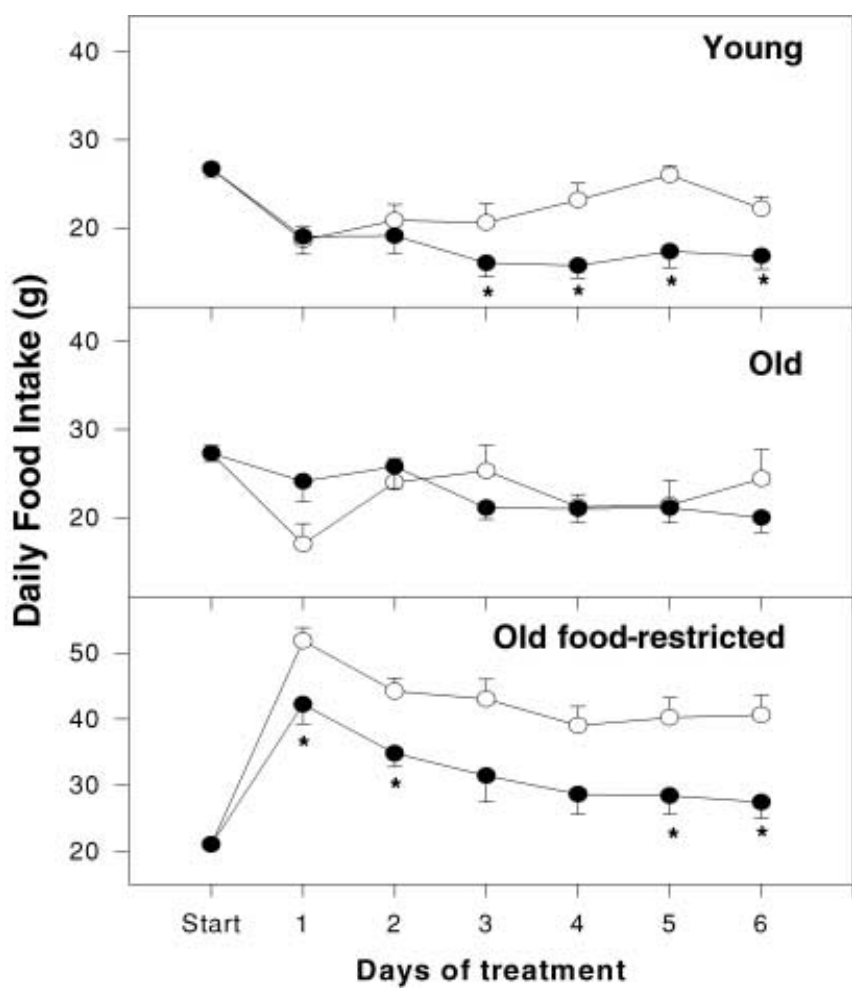

Fig. 3. Daily food intake of young, old and food-restricted old rats during treatment with either saline or $0.2 \mu \mathrm{g} /$ day of leptin. Data of daily chow consumed by young, old and food-restricted old Wistar rats during 6 days of treatment with saline $(\bigcirc)$ or $0.2 \mu \mathrm{g} /$ day of leptin $(\mathbf{O})$. Data are means \pm SEM of five rats per group. Daily food intake at start represents the mean value of food intake during a week before pump implantation in young and old rats fed ad libitum. Food-restricted old rats were provided with $21 \mathrm{~g}$ of chow daily before pump implantation. Twoway ANOVA indicates a significant effect of leptin treatment on food intake for young $(p=0.0007)$ and food-restricted old rats $(p<0.0001)$. One-way ANOVA shows a significant effect of the time of treatment in leptin-infused young $(p=0.003)$ and food-restricted old $(p=0.02)$ rats and in vehicle-treated foodrestricted old rats $(p=0.043)$. ${ }^{*} p<0.05$ compared with vehicletreated rats 


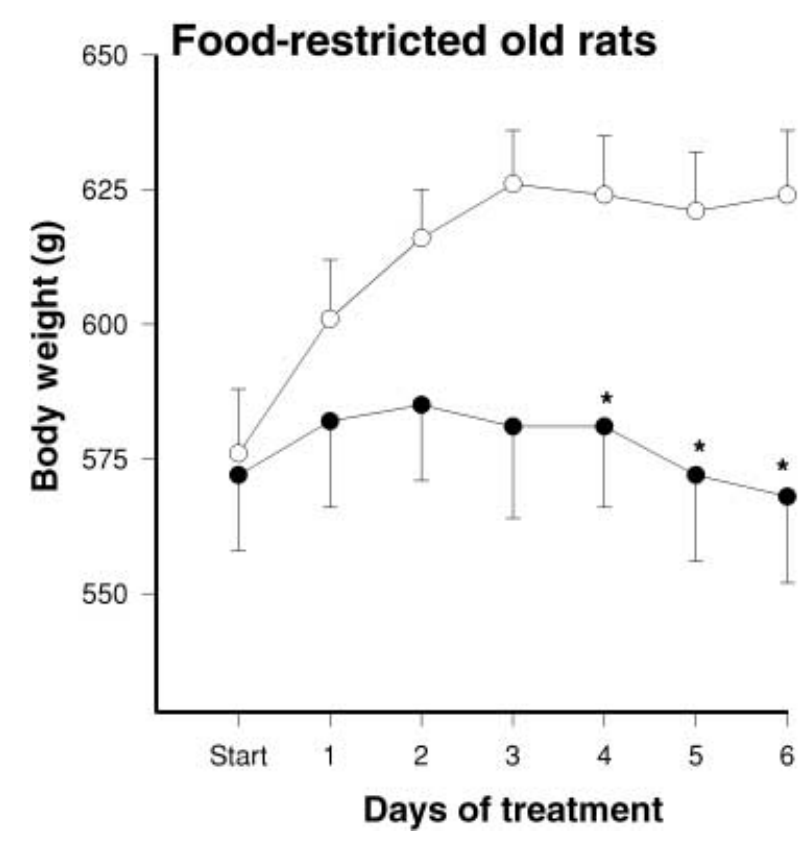

Fig. 4. Evolution of body weight of food-restricted old rats during treatment with either saline or $0.2 \mu \mathrm{g} /$ day of leptin. Osmotic minipumps containing saline $(\bigcirc)$ or leptin $(\bullet)$ were implanted in food-restricted old rats, and the rats were fed during 6 days. Figure shows the evolution of body weight throughout the treatment. Data are means \pm SEM of five animals per group. Two-way ANOVA shows an effect of leptin treatment $(p<0.0001)$ on body weight. One-way ANOVA shows an increase in body weight during the treatment for vehicle-treated animals $(p=0.048)$. $* p<0.05$ compared with vehicle-treated rats test indicated an effect of food restriction on $\Delta$ Lee Index $(p<0.0001)$ and serum leptin $(p=0.01)$. On the other hand, i.c.v. infusion of leptin did not increase serum leptin concentrations in any of the groups.

The effects of i.c.v. administration of leptin $(0.2 \mu \mathrm{g} /$ day $)$ on daily food intake in young, old and food-restricted old rats during treatment is shown (Fig. 3). Saline-infused young and old rats had a transient decrease in food intake in the first day after surgery but they had a rapid recovery with no differences from their previous records of food intake. In contrast, saline-infused food-restricted animals showed an increase in daily food intake compared with the old rats fed ad libitum, in spite of surgery. The i.c.v. infusion of $0.2 \mu \mathrm{g} /$ day of leptin lowered daily food intake in young but not in old rats fed ad libitum. The same dose of leptin in food-restricted old rats decreased food intake compared with saline-treated rats.

The evolution of body weight in food-restricted old rats when the dose of $0.2 \mu \mathrm{g} /$ day was administrated is shown (Fig. 4). Saline-treated rats increased in body weight during 3 days reaching a plateau thereafter. Leptin infusion prevented the above-mentioned increase, showing a tendency to lower this parameter.

The first step of leptin action is mediated by its receptor. Therefore, the expression of leptin receptor $(\mathrm{Ob}-\mathrm{Rb})$ was also studied. Figure 5 shows representative pictures of leptin receptors detected by immunohistochemistry. A clear decrease in the amount of leptin receptor was found in old rats. Food restriction

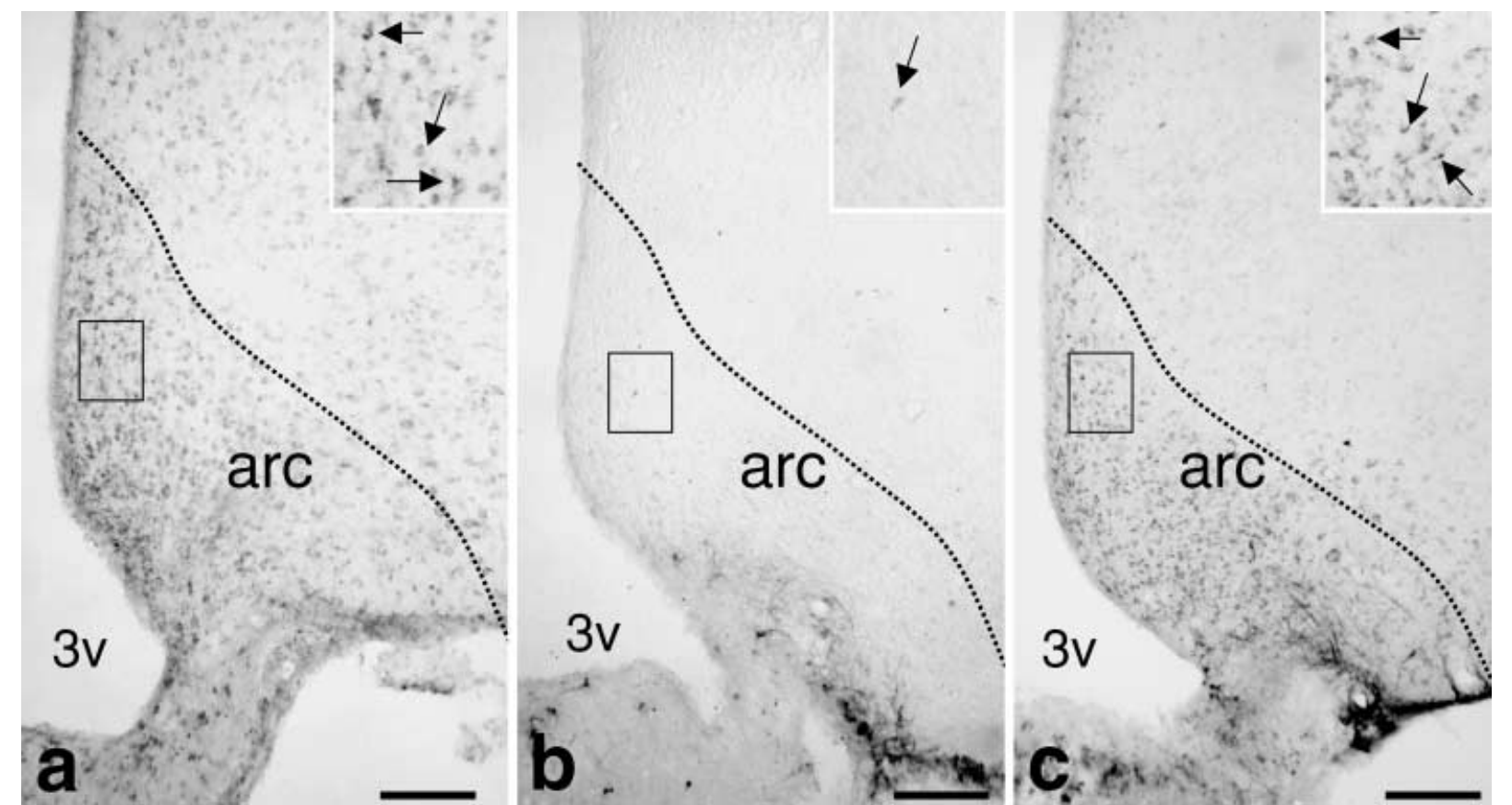

Fig. 5a-c. Leptin receptor immunoreactivity in the arcuate nucleus and the wall of the third ventricle. Immunoreaction using a polyclonal antiserum against a peptide mapping the carboxy terminus of leptin receptor in representative frontal sections from young (a), old (b) and food-restricted old (c) rats as de- scribed in Methods. The pattern was reproduced in 4-5 different rats per group. Inserts on the upper right corners of each picture correspond to magnification $(2.5 \times)$ of marked areas. Arrows point to inmunoreactive cells. Bars represent $150 \mu \mathrm{m}$. arc, arcuate; $3 \mathrm{v}$, third ventricle 


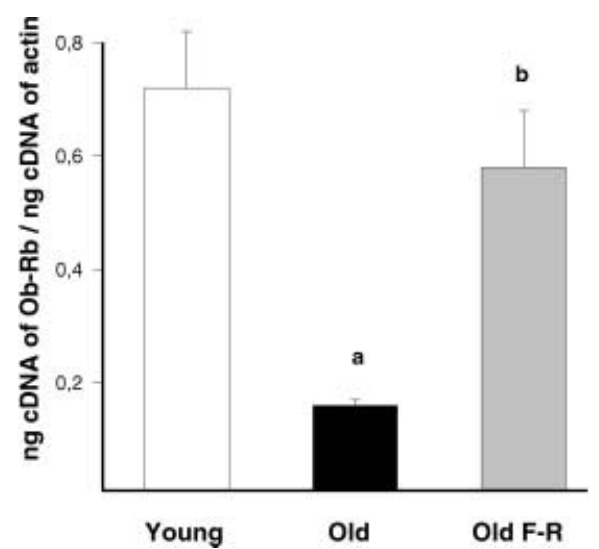

Fig. 6. Expression of $\mathrm{Ob}-\mathrm{Rb}$ in hypothalamus. Expression of $\mathrm{Ob}-\mathrm{Rb}$ in hypothalamus from young, old and old food-restricted rats was analysed by RT-PCR as indicated in Methods and is quantified as the ratio of $\mathrm{ng}$ of $\mathrm{Ob}-\mathrm{Rb} \mathrm{cDNA}$ amplified per ng of cDNA of actin under the reaction of conditions used. Values are means \pm SEM of four separate measurements per group of rats. a $p<0.005$ significantly different compared with young rats. $\mathrm{b} p<0.01$ significantly different compared with old rats. F-R, food-restricted

dramatically increased the detection of leptin receptor in the arcuate and periventricular nuclei compared with non-restricted old rats. Consistent with this data, $\mathrm{Ob}-\mathrm{Rb}$ leptin receptor mRNA levels in the hypothalamus of old rats were lower than in the young rats and food restriction almost restored this parameter to the values observed in young rats (Fig. 6).

\section{Discussion}

In agreement with previous reports [7], our data show that old Wistar rats have higher concentrations of serum leptin and adiposity than control mature adult animals. This, together with the fact that body weight and daily food intake are also higher in old than in young rats [7], suggest that old Wistar rats present leptin resistance. This agrees well with the data of other authors who described leptin resistance in other rodent models of ageing [12, 13, 18, 23]. A decrease in the ratio CSF-to-serum leptin concentrations suggested that a failure at the level of the transport from blood to CSF could be the cause of leptin resistance in obese humans [8]. This also has been reported in another experimental model with leptin resistance such as the New Zealand obese mice [10]. These animals respond to i.c.v. leptin administration with similar sensitivity as lean mice but did not respond to peripheral leptin administration. In old obese Fisher 344XBN rats, leptin resistance has been reported to occur at the central level $[13,24]$ and to involve alterations in leptin signal transduction cascade $[12,13]$.

To study whether or not aged Wistar rats have central leptin resistance, we studied the physiologic effects of i.c.v. administration of leptin. Vehicle- infused rats were used in comparison with leptintreated rats to evaluate the possible influence of surgery on the different parameters tested. Although the loss of body weight in old rats is higher than in young rats, these changes amounted some $2 \%$ and $3 \%$ for young and old rats respectively. This might be due to a more difficult recovery from surgery in the case of old rats. Nevertheless, daily food intake was not altered compared with its previous records before pump implantation with the exception of the first day, probably due to the surgery.

Our data shows that i.c.v. infusion of leptin specifically induces decreases in body weight, food intake and Lee index in a dose-dependent manner in young and old rats. Moreover, leptin treatment was effective without increasing serum leptin concentrations, indicating that the observed effects were achieved through the central action of leptin and not by its peripheral action due to a possible leakage of the hormone from CSF to blood.

Of interest, young and old rats treated with the highest dose of leptin undergo similar decreases in food intake but when a lower dose is used, the response in old rats is reduced. When daily food intake was calculated per unit of body weight, young rats showed a higher value than old rats but the pattern of response to leptin remained similar to that mentioned above. Young rats respond to low and high doses of leptin, whereas old rats show only a response to the highest dose used (data not shown). These data show that old Wistar rats have central leptin resistance during ageing and that this resistance could be due to decreased sensitivity. Nevertheless, a decreased maximum responsiveness cannot be ruled out. Accordingly, the specific effect of leptin on body weight loss was similar in both groups of rats with the highest dose of leptin used but when a lower dose was administrated, old rats showed a very poor response. Data showing lower effects on food intake and body weight reduction using acute daily i.c.v. administration of leptin in old Fisher $344 \mathrm{XBN}$ rats have been described by others [24]. A decreased maximum response, rather than a decreased sensitivity has been reported after central administration of leptin in old Fisher 344XBN rats [13]. This discrepancy, apart from differences in the rat model, could rely on the methodological approaches used in each case: an in vitro assay such as STAT-3 phosphorylation after acute injections of leptin in Fisher 344XBN rats [13] versus in vivo responses under lower amounts of leptin chronically infused.

The decreased responsiveness to i.c.v. administration of leptin in old Wistar rats could be the result of ageing, increased adiposity, or the combination of both circumstances. Long-term (3 months) physiologic food restriction in old rats induces a decrease in body weight and brings adiposity and serum leptin concentrations near to those of young rats. This allows the effect of central administration of leptin in old rats with adiposity and serum leptin concentrations close to 
those of young rats to be studied. Although the decrease in adiposity index in saline-infused foodrestricted rats does not reach statistical significance compared with the old rats fed ad libitum, this can be explained by the increase of daily food intake observed after 3 months of food restriction. Nevertheless, our data shows that i.c.v. infusion of leptin to aged foodrestricted rats reduces food intake and prevents the increase in body weight compared with saline-infused control rats, indicating that these rats recover the ability to respond to the lower dose of leptin used. Although some effects due to ageing alone cannot be ruled out, these data suggest that the increase of adiposity plays a key role in the development of central leptin resistance associated with ageing.

The decreased responsiveness of old Wistar rats is in agreement with the reported decreased uptake of leptin by hypothalamic nuclei and expression of $\mathrm{Ob}-\mathrm{Rb}$ leptin receptor in these rats [7]. Concerning the mechanisms responsible for the lower presence of $\mathrm{Ob}-\mathrm{Rb}$ in old rats, it seems possible that the increased concentrations of serum leptin, characteristic of these rats, might lead to a desensitisation or to down-regulation . In this sense, our data shows that food restriction lowers serum leptin concentrations and leads to an increase in the $\mathrm{Ob}-\mathrm{Rb}$ leptin receptor expression in the hypothalamus. This could explain, in part, the improved leptin responsiveness of food-restricted old rats. Nevertheless, our reported decreases in the expression of $\mathrm{Ob}-\mathrm{Rb}$ leptin receptor during ageing could also be another manifestation of ageing and/or obesity not directly related to a down-regulation process. On the other hand, the fact that food-restricted old rats, though centrally treated with leptin, show higher daily food intake than the old rats fed ad libitum, indicates that other factors, besides central leptin should also play a role in energy balance.

In conclusion, our work, besides the existence of central leptin resistance in the old Wistar rat, shows that food restriction restores leptin responsiveness and increases leptin receptor expression, supporting the key role of age-associated adiposity in the development of leptin resistance.

Acknowledgements. Grant 2FD 1997-1754-CO31-3 from DGESIC. Financial aid from Química Farmacéutica Bayer (Spain) is acknowledged. The Centro de Biología Molecular is the recipient of institutional aid from the Ramón Areces Foundation. C. Pérez is a recipient of a fellowship from Mutis Programe, AECI.

\section{References}

1. Zhang Y, Proenca R, Maffei M, Barone M, Leopold L, Friedman JM (1994) Positional cloning of the mouse obese gene and its human homologue. Nature 372:425-432

2. Friedman JM, Halaas JL (1998) Leptin and the regulation of body weight in mammals. Nature 395:763-770

3. Schwartz MW, Woods SC, Porte Jr. D, Seeley RJ, Baskin DG (2000) Central nervous system control of food intake. Nature 404:661-671
4. Spiegelman BM, Flier JS (2001) Obesity and the regulation of energy balance. Cell 104:531-543

5. Tritos NA, Mantzoros CS (1997) Leptin: its role in obesity and beyond. Diabetologia 40:1371-1379

6. Li H, Matheny M, Nicolson M, Tümer N, Scarpace PJ (1997) Leptin gene expression increases with age independent of increasing adiposity in rats. Diabetes 46:2035-2039

7. Fernández-Galaz C, Fernández-Agulló T, Campoy F et al. (2001) Decreased leptin uptake in hypothalamic nuclei with ageing in Wistar rats. J Endocrinol 171:23-32

8. Caro JF, Kolaczynski JW, Nyce MR et al. (1996) Decreased cerebrospinal-fluid/serum leptin ratio in obesity: a possible mechanism for leptin resistance. Lancet 348:159-161

9. Schwartz MW, Peskind E, Raskind M, Boyko EJ, Porte D Jr (1996) Cerebrospinal fluid leptin levels: relationship to plasma levels and to adiposity in humans. Nat Med 2:589593

10. Halaas JL, Boozer C, Blair-West J, Fidahusein N, Denton DA, Friedman JM (1997) Physiological response to long-term peripheral and central leptin infusion in lean and obese mice. Proc Natl Acad Sci USA 94:8878-8883

11. El-Haschimi K, Pierroz DD, Hileman SM, Bjørbaek C, Flier JS (2000) Two defects contribute to hypothalamic leptin resistance in mice with diet-induced obesity. J Clin Invest 105:1827-1832

12. Scarpace PJ, Matheny M, Shek EW (2000) Impaired leptin signal transduction with age related obesity. Neuropharmacology 39:1872-1879

13. Scarpace PJ, Matheny M, Tümer N (2001) Hypothalamic leptin resistance is associated with impaired leptin signal transduction in aged obese rats. Neuroscience 104:1111-1117

14. Nishimura H, Kuzuya H, Okamoto M et al. (1988) Change of insulin action with ageing in conscious rats determined by euglycemic clamp. Am J Physiol 254:E92-E98

15. Escrivá F, Agote M, Rubio E et al. (1997) In vivo insulindependent glucose uptake of specific tissues is decreased during ageing of mature Wistar rats. Endocrinology 138:4954

16. Widdowson PS, Upton R, Buckingham R, Arch J, Williams G (1997) Inhibition of food response to intracerebroventricular injection of leptin is attenuated in rats with diet-induced obesity. Diabetes 46:1782-1785

17. Paxinos G, Watson C (1997) The rat brain in stereotaxic coordinates, 3rd edn. Academic Press, San Diego

18. Scarpace PJ, Matheny M, Moore R-L, Tumer N (2000) Impaired leptin responsiveness in aged rats. Diabetes 49:431-435

19. Shu SY, Ju G, Fan LZ (1988) The glucose oxidase-DABnickel method in peroxidase histochemistry of the nervous system. Neuroscience 85:169-171

20. Sambrook J, Fritsch EF, Maniatis T (1989) Molecular Cloning: a laboratory manual, 2nd edn. Cold Spring Harbor Laboratory Press, New York

21. Chen H, Charlat O, Tartaglia LAA et al. (1996) Evidence that diabetes gene encodes the leptin receptor: identification of a mutation in the leptin receptor gene $\mathrm{db} / \mathrm{db}$ mice. Cell 84:491-495

22. Tokunaga K, Taniguchi H, Yoda K, Shimizu M, Sakiyama S (1986) Nucleotide sequence of a full-length cDNA for the mouse cytoskeletal $\beta$-actin mRNA. Nucleic Acids Res 14:2892

23. Quian H, Azain MJ, Hartzell DL, Baile CA (1998) Increased leptin resistance as rats grow to maturity. Proc Soc Exp Biol Med 219:160-165

24. Sheck EW, Scarpace PJ (2000) Resistance to the anorexic and thermogenic effects of centrally administrated leptin in obese aged rats. Regul Pept 92:65-71 